$\begin{array}{ll} & \text { Etnográfica } \\ \text { etnográfica } & \text { Revista do Centro em Rede de Investigação em }\end{array}$

Antropologia

vol. $20(3) \mid 2016$

Vol. 20 (3)

\title{
Cuidar, curar, resistir: corporeidade e violências entre mulheres tembé-tenetehara (Santa Maria,
} PA)

Care, healing, and resistance: corporeity among Tembé-Tenetehara women (Santa Maria, PA)

\section{Camille Gouveia Castelo Branco Barata}

\section{QpenEdition}

\section{Journals}

\section{Edição electrónica}

URL: https://journals.openedition.org/etnografica/4668

DOI: 10.4000/etnografica.4668

ISSN: 2182-2891

\section{Editora}

Centro em Rede de Investigação em Antropologia

\section{Edição impressa}

Data de publição: 1 outubro 2016

Paginação: 565-581

ISSN: 0873-6561

\section{Refêrencia eletrónica}

Camille Gouveia Castelo Branco Barata, «Cuidar, curar, resistir: corporeidade e violências entre mulheres tembé-tenetehara (Santa Maria, PA)», Etnográfica [Online], vol. 20 (3) | 2016, posto online no dia 27 novembro 2016, consultado o 11 fevereiro 2022. URL: http://journals.openedition.org/ etnografica/4668 ; DOI: https://doi.org/10.4000/etnografica.4668

\section{(c) (7) \&}

Etnográfica is licensed under a Creative Commons Attribution-NonCommercial 4.0 International License. 


\section{Cuidar, curar, resistir: corporeidade e violências entre mulheres tembé-tenetehara (Santa Maria, PA)}

\section{Camille Gouveia Castelo Branco Barata}

O trabalho problematiza as práticas de cuidado e proteção do corpo frente a situações de violência entre as mulheres tembé-tenetehara moradoras do hoje município brasileiro de Santa Maria do Pará. Consiste na revisão bibliográfica empreendida sobre as questões da pesquisa, bem como na reflexão sobre narrativas consideradas reveladoras para o entendimento do tema. Os objetivos são: (1) dialogar com o repertório bibliográfico investigado até o momento a partir dos atos e falas das interlocutoras, considerando as interpretações antropológicas e as das interlocutoras igualmente válidas; (2) refletir sobre as formas de empoderamento, cuidado e resistência das interlocutoras frente a situações de violência e brutalização dos corpos e trajetórias. Categorias como dor e terror, bem como o entendimento de marcadores sociais da diferença sob um ponto de vista interseccional estruturam o olhar sobre a pesquisa.

PALAVRAS-CHAVE: cuidado, corporeidade, mulheres tembé-tenetehara.

Care, healing, and resistance: corporeity among Tembé-Tenetehara women (Santa Maria, PA) - The article discusses the practices of care and protection of the body against situations of violence among women Tembé-Tenetehara living in the district of Santa Maria do Pará, Brazil. It focuses on the review of relevant bibliography on the issues under research, as well as on narratives considered revealing to a better understanding of the subject. The objectives are (1) to dialogue with the bibliographical repertoire called for the acts and statements of interlocutors, considering anthropological interpretations and the interlocutors' interpretations as equally valid; (2) to discuss the forms of empowerment, care and resistance of the interlocutors in situations of violence and brutalization of bodies and trajectories. Categories such as pain and terror, and the understanding of social markers of difference under an intersectional perspective structure this overlook upon the ongoing research.

KEYWORDS: care, corporeality, Tembé-Tenetehara women.

BARATA, Camille Gouveia Castelo Branco (camillecastelobranco@gmail.com) Programa de Pós-Graduação em Antropologia, Universidade Federal do Pará, Brasil. 


\section{INTRODUÇÃO}

A presente discussão insere-se no projeto de pesquisa intitulado "Pertenças ocultas e 'etnogêneses' identitárias como faces de etnocídio 'cordial': antropologias e histórias 'em suspenso' entre os tembé/tenetehara no rio Guamá”. ${ }^{1}$ Tem por temática o cuidado, a corporeidade e povos indígenas e por objeto as práticas de cuidado e proteção do corpo frente a situações de violência entre as mulheres tembé-tenetehara moradoras do hoje município de Santa Maria do Pará.

Trata-se de uma ampliação renovada ${ }^{2}$ da pesquisa anteriormente empreendida em diálogo com mulheres tembé-tenetehara, cuja atenção era voltada para os modos como a corporeidade ${ }^{3}$ dizia do gênero ${ }^{4} \mathrm{e}$ da etnicidade, ${ }^{5}$ marcadores sociais da diferença que especificam a enunciação das protagonistas com quem se dialoga. Em 2013, antes de ir a campo, ainda fazendo o levantamento bibliográfico e tentando definir referenciais teóricos, o foco da pesquisa se direcionava para a corporeidade analisada sob um ponto de vista estético: nesse período, a intenção era analisar o grafismo e a pintura corporal, tendo como inspirações trabalhos seminais como o de Lux Vidal (2000).

1 Este artigo foi contemplado com o segundo lugar do Prêmio Lévi-Strauss 2016 (modalidade B), promovido pela Associação Brasileira de Antropologia (ABA). O projeto mencionado foi realizado sob orientação da professora doutora Jane Felipe Beltrão e contou com apoio e financiamento do Conselho Nacional de Desenvolvimento Científico e Tecnológico (CNPq), associado à bolsa de produtividade em pesquisa (nível IC) do CNPq, processo n. ${ }^{\circ}$ 303027/2013-4/CNPq. Parte dos resultados da pesquisa pode ser conferida em Barata e Beltrão (2014).

2 Na estruturação desse novo momento de pesquisa, agradeço especialmente a Rosani de Fátima Fernandes e Paula Mendes Lacerda, cujas inflexões, questionamentos e contribuições foram de grande importância para os direcionamentos do trabalho.

3 As formulações teóricas que demonstram maior adequação ao que se pretende na pesquisa são aquelas elaboradas por Thomas Csordas (1990), especialmente no que tange ao conceito de embodiment ("corporificação", em tradução livre), que propõe um novo paradigma nos estudos da corporeidade, segundo o qual o corpo é pensado como "sujeito da cultura", como a "base existencial da cultura", dotado de agência própria. Não apenas como receptáculo de símbolos culturais, mas como produtor de sentido, uma entidade social experiencial, atuante e interpretadora.

4 Entendo que a categoria gênero se relaciona com as reflexões de Joan Scott (1995), para quem gênero é: (1) um elemento constitutivo das relações sociais baseadas nas diferenças percebidas entre os sexos e (2) uma forma primária de dar significado às relações de poder. A partir de Scott (1995), o termo ganha status de categoria analítica, de instrumento metodológico para o entendimento da construção, da reprodução e das mudanças das identidades de gênero. A autora assevera que tal categoria deve ser analisada sob um ponto de vista relacional, tendo em vista a especificidade dos contextos nos quais que se constrói. Tais formulações permitem dar um passo inicial no sentido de evitar essencializações homogeneizantes sobre os povos indígenas.

5 Entendo a categoria etnia a partir das considerações de Barth (2000), para quem os grupos étnicos devem ser reconhecidos a partir da fronteira que estabelecem em relação aos demais grupos, fronteira criada em face das diferenças identificadas pelos próprios membros do grupo em relação aos outros. Tais diferenças, portanto, estão imersas em relações de alteridade. 
Porém, o trabalho de campo, complexo, surpreendente e dinâmico como é, apresentou uma versão do objeto de pesquisa que não se previu, pois as corporeidades reveladas em diálogo e aprendizado com as tembé-tenetehara estavam atravessadas de forma indelével por episódios de violência (ou "massacre" e "escravização", como as protagonistas referiram) vividos como eventos devastadores, e em muitos casos diariamente reencenados e dramatizados pelo não acesso a direitos compreendidos como fundamentais.

Nas gramáticas corporais que emergiram em campo, a estética, embora em muitos momentos venha à cena suscitando tensões, não parecia ser a questão principal. Mais relevante era saber cuidar de si e dos seus, protegendo e curando o corpo, lutando ${ }^{6}$ por reconhecimento e buscando tornar espaços marcados pela "dor" e pelo "sofrimento" novamente habitáveis (Das 2008a). A partilha do tempo (Oliveira 2004) com as interlocutoras, à época, modificou as questões enfatizadas na pesquisa. Os desdobramentos dessa partilha repercutem na abordagem feita nesse momento.

A aproximação com as interlocutoras se deu a partir da circulação em meio a atividades cotidianas que as mesmas realizavam. Ajudar a lavar a louça, limpar a mesa, fazer café, assistir a novela e varrer a casa possibilitaram os diálogos mais frutíferos e a escuta dos depoimentos mais desenvoltos. Posteriormente, pude perceber que o espaço da casa é um cenário visceral de decisão política na comunidade, onde o protagonismo das interlocutoras se exerce de forma contundente. As decisões "oficiais", proferidas em público pelos homens nas assembleias indígenas, só são tomadas a partir da escuta prévia das mulheres, dentro das casas.

Esta discussão consiste na revisão bibliográfica empreendida sobre as questões da pesquisa, bem como na reflexão sobre narrativas consideradas reveladoras para o entendimento do tema. Os objetivos, são: (1) refletir sobre as formas de empoderamento, cuidado e resistência das interlocutoras frente a situações de violência e brutalização dos corpos e trajetórias; (2) dialogar com o repertório bibliográfico investigado até o momento a partir dos atos e falas das interlocutoras, considerando as interpretações antropológicas e as das interlocutoras igualmente válidas.

\section{PERSPECTIVAS TEÓRICAS E DECISÕES METODOLÓGICAS}

Da família linguística tupi-guarani, do tronco tupi, os tembé, ou como também se autonomeiam, os tenetehara, moradores de Santa Maria do Pará, são pouco conhecidos na literatura etnológica nacional. A história do povo tembé, assim como da maioria dos povos indígenas do Brasil, é marcada por transformações produzidas pelo contato com a sociedade envolvente. Gomes (2002), 
ao escrever sobre os tembé-tenetehara, afirma que seus membros saíram dos territórios nas proximidades do rio Pindaré, no Maranhão, migrando para o rio Gurupi, divisa dos estados do Pará e Maranhão, posteriormente indo para o alto dos rios Capim e Guamá, no estado do Pará, até as proximidades dos rios Maracanã, Prata e Jeju no nordeste do Pará.

Wagley e Galvão (1955) previram, em seus estudos, o desaparecimento dos tenetehara em função de uma suposta "fragilidade" e "homogeneidade" do discurso cosmológico e da vida religiosa dessas sociedades. Segundo os autores, em função do contato com a cultura europeia, "[o] processo de transformação dos tenetehara em caboclos está em vias de se completar no espaço de uma geração ou um pouco mais" (Wagley e Galvão 1955: 185).

Embora a história e as trajetórias de vida dos tembé em Santa Maria demonstrem que a "profecia antropológica" não se realizou, as falas dos dois antropólogos revelam o que os estudos descoloniais denominam como uma das "faces ocultas da modernidade": a colonialidade. ${ }^{7}$ A "mão pesada" da colonialidade incide sobre os povos indígenas, se não levando à exterminação física, conduzindo ao apagamento e à repressão de suas línguas nativas, cosmologias e modos de vida.

No caso dos tembé em Santa Maria, este processo assume contornos específicos, pois se relaciona com a cristianização forçada desse povo a partir da ação missionária no território indígena, cujas principais fontes históricas reportam ao ano de 1913. Parte do projeto dito "civilizador" empreendido por esses agentes é elucidado pelo contexto estabelecido na Colônia Santo Antônio do Prata, educandário que recebia as crianças indígenas sequestradas de suas comunidades e apartadas de seus parentes para serem educadas, catequizadas e "civilizadas" com base na pedagogia cristã dos missionários capuchinhos.

Beltrão (2012) explica que o projeto introduziu 25 famílias de colonos entre as 55 famílias indígenas, estendendo o raio de ação para além dos limites do Prata, alcançando as vilas de Jambuaçu e Castanhal. A estratégia era retirar indígenas crianças e jovens das famílias de origem, impedindo-os de ser educados entre os pais. A autora também descreve as formas de resistência realizadas pelos indígenas na época, dentre as quais a embriaguez se destaca como o momento em que os pais iam ao encontro dos filhos tomados, reivindicando sua volta. Os (des)caminhos da trajetória do povo tembé-tenetehara se

7 Quijano (2005) compreende a colonialidade como um padrão de poder fundado com a invasão das Américas e que se mantém em tempos atuais, tendo o eurocentrismo, o capitalismo e a classificação racial da população mundial como eixos estruturais. As considerações de Quijano (2005) fazem parte do chamado pensamento descolonial, campo de estudos formado por intelectuais latino-americanos que analisam, por meio de uma historiografia crítica, as especificidades das regiões da América Latina em relação à experiência da colonização. 
relacionam, portanto, com histórias de violações de direitos, ou o que Beltrão (2012) caracteriza como etnocídio "cordial". Trata-se de uma trajetória que diz das resistências e agenciamentos dos tembé em relação a um longo período em que dizer-se indígena era assinar sentença de morte.

Perseguindo a possibilidade de evitar estereotipias e o essencialismo, procurei, ao longo da pesquisa, frisar a agência e o protagonismo das tembé-tenetehara, não as representando como vítimas passivas, assoladas e paralisadas pela violência, especialmente masculina. Essa forma de descrição se afinaria com as representações racistas e colonizadoras que marcam a história dos povos indígenas no Brasil, representações que colocam as trajetórias das indígenas mulheres em um lugar de instransponível barbarismo e selvageria. Compreender os relatos das interlocutoras como parte de um contexto dinâmico e aberto a continuidades, mudanças e resistências é, portanto, essencial para as aspirações do trabalho.

Posto isso, ressalto que, para os limites desse trabalho, não há pretensão alguma de exterioridade ou neutralidade no trato das questões abordadas. A investigação é contaminada desde a partida: (1) nas motivações que a originaram; (2) na solidariedade e empatia com relação à causa das interlocutoras antes mesmo de conhecê-las, ouvindo os relatos de pesquisadores que já realizavam diálogos com estas; e, finalmente, (3) na execução do campo e da escrita.

De fato, acredito que em contextos onde o terror (Taussig 1993) se dá de forma contundente, não se posicionar é, a princípio, se posicionar. Considero que a não escolha de um "lado", em determinados contextos de pesquisa, pode significar escolher o lado oposto ao dos interlocutores, produzindo antagonismos mais ou menos intencionais e contrariando, inclusive, os princípios éticos da Associação Brasileira de Antropologia (ABA). Evidentemente, optar pela adesão à causa das protagonistas com quem dialogo, bem como pela convergência em relação à suas sensibilidades e interpretações transforma tanto o que é dito, quanto o não dito no trabalho.

Concordo com as formulações de Pacheco de Oliveira (2004), para quem a recomendação metodológica de neutralidade é uma ficção de natureza política que legitima relações de dominação colonial. O diálogo pretensamente neutro reproduz o modelo de comunicação "informante-nativo", em tudo o que tem de assimétrico e vertical. Para o autor, homogeneizar a variedade de relações possíveis a partir do diálogo antropológico e suas repercussões na etnografia seria um procedimento reducionista e empobrecedor. Pacheco de Oliveira (2004) acrescenta que apenas uma atitude fundamentalista poderia deslegitimar etnografias tidas como mais "engajadas" e "militantes".

Roberto Cardoso de Oliveira (2005), refletindo a partir de relações interétnicas, defende que o reconhecimento identitário na contemporaneidade não é só uma questão política, mas, sobretudo, um imperativo moral. Nesse sentido, 
só pode haver escuta, diálogo e relação quando reconhecemos a identidade de quem nos fala. Entender como legítimas representações, valores e identidades das protagonistas, acompanhando o argumento do autor, passa a ser fundamental.

Veena Das (2008b) em seus escritos problematiza a correlação entre dor e linguagem. Segundo a autora, por meio da expressão da dor, é possível sair da privacidade sufocante dela. De acordo com Das (2008b), eventos devastadores produzem um tipo de conhecimento que só é alcançado pela experimentação do sofrimento, um "conhecimento venenoso". Portanto, violências extremas não seriam apenas responsáveis pela destruição de vidas e corpos. Atuam, também, na construção de sujeitos e linguagens da dor. A enunciação da dor pede, portanto, admissão e reconhecimento, o que nem sempre ocorre. Trata-se, nos termos da autora, de sentir a dor no corpo do outro. Essa é a proposta ao fazer antropológico.

Em trabalho de grande influência e repercussão, Gayatri Spivak (2010) questiona criticamente a (im)possibilidade de fala de determinados grupos. A autora constata que os subalternos em geral, e o sujeito historicamente emudecido da mulher subalterna em particular, foram e são, ao longo da história, mal compreendidos ou mal representados pelo interesse pessoal dos que têm poder para representar. A proposição instigante de Spivak (2010), além de elucidar silenciamentos, colonialismo e violência, também aduz escutas anti-hegemônicas, epistemologicamente desobedientes, descoloniais.

Inspirada pela reflexão provocativa da filósofa indiana, Paula Lacerda ${ }^{8}$ considera que, em meio a tentativas de silenciamento, os grupos e sujeitos subalternizados - e esse é um deslocamento analítico fundamental para que a subalternidade não seja entendida como lugar paralisante e intransponível estão falando. Superando a perspectiva colonialista que pretende "dar voz" aos grupos subalternizados por meio da pesquisa, Lacerda tensiona a questão que orienta Spivak (2010): como o não subalternizado, o privilegiado, pode escutar? As posições teórico-epistemológicas (que também possuem caráter político) adotadas na presente discussão objetivam favorecer a escuta etnográfica mais responsável, capaz de superar estereótipos de passividade e compreender as tembé-tenetehara como sujeitos de suas próprias histórias.

Complementando o argumento, aporto-me nas formulações de Esteban (2004), para quem uma antropologia - e pode-se aqui estender a colocação para as ciências humanas no geral - do corpo responsável e comprometida deve contribuir para a transformação social e para o empoderamento de sujeitos 
em situação de subalternização ou discriminação, como é o caso de indígenas mulheres. ${ }^{9}$

A pesquisa possui cunho etnográfico e aporta-se nas formulações de Geertz (1973), para quem a etnografia é uma forma de descrição da cultura, entendida como um sistema de símbolos construídos, passível do que o próprio Geertz (1973) denomina como "descrição densa". O autor considera que "[...] para entender as concepções alheias é necessário que deixemos de lado nossa concepção, e busquemos ver as experiências de outros com relação a sua própria concepção do 'eu'” (2007: 91), não encaixando experiências culturais diversas na moldura de nossa própria visão de mundo, relativizando certezas e convicções para perceber o "outro" a partir do local de onde fala.

As considerações de Cardoso de Oliveira (2006) fornecem subsídios para a estruturação da observação participante no contexto da comunidade. O autor compreende que o objeto para o qual dirigimos nosso olhar já foi previamente modificado por nosso modo de visualizá-lo, por estar condicionado por nossa disciplina formadora e por nossa forma de enxergar a realidade. Magnani (2009) recomenda um olhar "de perto e de dentro" que considere os arranjos dos próprios atores sociais e, aproximando-se do "olhar nativo", possa traduzi-lo a partir do aparato intelectual antropológico.

A necessidade de analisar as relações de gênero atentando para o contexto etnicamente diferenciado das mulheres tembé-tenetehara conduz à adoção da perspectiva interseccional proposta por Avtar Brah (2006) e Anne McClintock (2010). Brah (2006) operacionaliza o conceito de "interseccionalidade" por meio da noção de "diferença" como categoria analítica, tomando diferença de modo não essencial, mas como categoria que remete à designação de "outros", a fim de estudar "as inter-relações das várias formas de diferenciação social, empírica e historicamente, mas sem necessariamente derivar todas elas de uma só instância determinante" (2006: 33 l-332), tentando evitar o perigo do "reducionismo". McClintock (2010) toma classe, "raça" e gênero, como campos articulados da experiência, e não isolados uns dos outros ou simplesmente justapostos, mas que existem concretamente em e através de relações com cada um dos outros.

As fundamentações teóricas propostas por Lugones (2008) explicitam o entendimento de que não se pode analisar a situação de mulheres de cor (incluindo indígenas mulheres) sem que se considerem as vicissitudes do

9 No tocante à categoria de empoderamento, concordo com Kleba e Wendausen, para quem aquele refere-se ao "processo de mobilizações e práticas que objetivam promover e impulsionar grupos e comunidades na melhoria de suas condições de vida, aumentando sua autonomia" (2009: 735). O empoderamento não se constrói, portanto, a partir da verticalidade ou da filantropia (aqui entendidas como formas veladas de colonização e tutela): as pessoas e os grupos empoderam a si mesmos. Por meio das estratégias de empoderamento, os grupos e sujeitos capacitam-se para subverter as assimetrias de poder que os mantêm em situação de iniquidade. 
processo histórico e violento de dominação colonial, que inclui o que a autora denomina como sistema moderno e colonial de gênero. ${ }^{10}$ Este sistema se traduz pela brutalização, subordinação e desumanização de mulheres não brancas. Ainda, segundo a autora, a colonização branca e ocidental cooptou homens de cor, o que resulta na colaboração desses agentes para debilitar o poder das mulheres.

As considerações de Lugones (2008) remetem às de Segato (2003), pois, de acordo com a autora, ao replicar a linguagem do dominador, o agente subalternizado a desloca, desgasta e desestabiliza, erodindo a própria dialética dominador-dominado e introduzindo uma marca de insubordinação. Assumo que as percepções de Segato (2003) são elucidativas das possibilidades de agência - aqui utilizada no sentido atribuído por Pierre Bourdieu (1977) e Anthony Giddens (1984) - de sujeitos subalternizados, frente a relações de poder assimétricas. Ter em vista as diversas formas de exercício da agência permite compreender essas relações de forma mais nuançada.

Pacheco de Oliveira (1998) afirma, nesse sentido, que à imposição das normas dominantes, segue-se a apropriação local, sempre específica e individualizadora, para os povos indígenas. $\mathrm{O}$ autor acrescenta que a atualização e a mudança histórica a partir da colonialidade não anulam as identidades étnicas, pelo contrário, as reforçam a partir da fronteira da alteridade. O autor assevera ainda a necessidade de abandonar perspectivas que refletem sobre os povos indígenas tendo o isolamento como comprovação da autenticidade étnica. A autenticidade é vista como gueto criado para satisfazer o mundo dominante e pouco contribui para a reflexão sobre o caráter dinâmico e não estrutural da cultura, conduzindo, inclusive, às armadilhas da exotificação, ao radicalizar a diferença entre ameríndios e modernos, ignorando os vínculos históricos entre ambos.

\section{DIÁLOGOS E ESCUTAS ETNOGRÁFICAS: INTERFACES DA AÇÃO E DA MEMÓRIA DE MULHERES TEMBÉ-TENETEHARA}

Em uma noite de julho de 2014, eu estava na cozinha de Dona Cássia, onde tomávamos café e conversávamos antes de dormir. Naquele dia, sozinha com Dona Cássia, pela primeira vez emergiu uma história que até o momento havia apenas sido sugerida subliminarmente em outros diálogos. Trata-se de

10 Nas palavras da autora, referindo-se à expressão "mulheres de cor": "[n]o se trata simplemente de un marcador racial, o de una reacción a la dominación racial, sino de un movimiento solidario horizontal. Mujeres de color es una frase que fue adoptada por las mujeres subalternas, víctimas de dominaciones múltiples en los Estados Unidos. 'Mujer de color' no apunta a una identidad que separa, sino a una coalición orgánica entre mujeres indígenas, mestizas, mulatas, negras: cherokees, puertorriqueñas, sioux, chicanas, mexicanas, pueblo, en fin, toda la trama compleja de las víctimas de la colonialidad del género. Pero tramando no como víctimas, sino como protagonistas de un feminismo decolonial" (Lugones 2008: 75). 
acontecimento trágico ocorrido no passado com sua filha Carolina e que mudara a vida dela de modo definitivo. Falando baixo, enquanto era ouvida em silêncio, Dona Cássia narrou a história de sua filha, que ainda muito jovem, cursando o ensino fundamental, foi sequestrada por um homem, "um anjo mau" que circulava em Santa Maria, ameaçando a segurança das meninas que ali viviam e estudavam. O sujeito colocou Carolina no carro à força e a levou para uma propriedade escondida, onde durante oito dias a manteve, forçando a violência sexual enquanto ela buscava se defender e apanhava muito a cada tentativa.

O desaparecimento da filha mobilizou os familiares e amigos próximos de Dona Cássia e, quando a continuidade da procura era desencorajada, a interlocutora respondia que sentia dentro de si que iria encontrar a filha de novo. Passados sete dias, chegou a notícia do paradeiro da menina. O pai de Carolina, enfurecido pela situação em que fora encontrada, queimou os pertences da filha. Dona Cássia, com pesar, dirigiu-se ao local esperando que em breve fosse realizar um casamento. Somente ao encontrar e conversar com a filha descobriu o que de fato havia acontecido. Dona Cássia levou a filha para casa e desdobrou-se para que o pai acreditasse que Carolina havia sido sequestrada e violentada e não possuía nenhum tipo de relação com aquele homem. Ele tinha muito dinheiro, o que à época assegurou-lhe a impunidade.

Carolina, por outro lado, precisou continuar frequentando a escola, pois para os tembé-tenetehara a educação escolar é um meio de assegurar o estabelecimento de melhores condições de vida, bem como o fortalecimento da comunidade na luta por direitos e reconhecimento. Foi caminhando até a escola que Carolina foi novamente sequestrada pelo criminoso que permaneceu solto da primeira vez, e levada para uma propriedade ainda mais escondida, onde novas violências foram enfrentadas pela menina. $\mathrm{O}$ desespero de perceber que a filha não havia voltado para casa depois da aula motivou Dona Cássia a empreender novas buscas, bem como a iniciar orações para que Deus a ajudasse a encontrar a filha. Nesse período, ela teve uma visão que mostrou como era a casa onde estava Carolina. Dona Cássia fez a descrição para todas as pessoas envolvidas na busca e chegou a percorrer a cidade no carro do irmão, procurando um lugar semelhante, sem sucesso.

Passados alguns dias, ainda mantida sob cárcere, Carolina enxergou uma pessoa passando pela casa onde estava e, aproveitando a momentânea ausência do sujeito que a sequestrou, a menina chamou um rapaz que caminhava ali perto, pediu que ele telefonasse para a casa de sua mãe e explicasse onde ela estava e o que havia acontecido. Anotou o número de sua casa na palma da mão para mostrar para o rapaz que poderia ajudá-la e esperou que a encontrassem. Porém, ela esqueceu-se de apagar o número escrito e, quando o homem retornou a casa, viu sua mão e compreendeu que ela havia se comunicado em busca de ajuda. Ele espancou-a brutalmente e abandonou-a quase morta na propriedade. 
As buscas continuaram e o tio de Carolina, percorrendo a cidade atrás da sobrinha, passou em frente a uma casa exatamente como a que fora descrita por Dona Cássia em sua visão. Resolveu entrar e encontrou a sobrinha inconsciente e muito machucada. Levou-a para casa e decidiu não contar o que havia acontecido para a mãe, no princípio. Ele telefonou para a irmã, disse que estava com Carolina, mas a impediu de ver a filha, dado o estado em que se encontrava. Dona Cássia, posteriormente, encontrou Carolina acordada, com o corpo escurecido dos pés à cabeça por hematomas.

A família levou a menina ao encontro de um jovem evangélico, bastante conhecido por suas pregações. Dona Cássia conta que parecia que "Deus estava falando pela boca desse moço, ele disse tudo o que ia no meu coração e no da minha filha, foi uma coisa tão emocionante e linda que eu me senti confortada, nos deu força pra começar de novo". Não creio que seja por acaso que Carolina, hoje adulta, seja evangélica. Também não acredito que se trate de coincidência que ela seja a pessoa a quem todos recorrem na comunidade quando estão doentes, uma vez que se dedica pessoalmente e com afinco a conseguir de remédios a ambulâncias e leitos hospitalares para quem estiver precisando. Carolina é uma cuidadora, uma agente de saúde comunitária. Garantir que os membros da comunidade tenham acesso à atenção à saúde de forma adequada é imperativo para impedir que outras violências, como as que marcam sua trajetória, sejam cometidas contra os corpos de seus pares.

O evento narrado por Dona Cássia assume contornos ainda mais dolorosos em função de ela própria, quando jovem, ter escapado de uma tentativa de estupro quando precisou afastar-se da família e ir morar com a madrinha para dar continuidade aos estudos no ensino médio, que não era ofertado nas proximidades de sua comunidade. Assistir a um momento tão difícil de sua própria vida ser repetido e, pior, efetivado, de forma truculenta com a própria filha diz de processos cruéis de produção de corpos e vidas dispensáveis (Vianna e Farias 2011), a partir da presença de certos marcadores sociais da diferença que, entrecruzados, engendram desigualdades e assimetrias de poder.

A repetição da violação na história pessoal de mãe e filha parece revelar outro aspecto, além da referida dispensabilidade de certos corpos: o estupro que marca a história desses mesmos corpos. Essa é uma dimensão refletida por Andrea Smith (2014), membro do povo cherokee, que compreende a violência sexual como ferramenta de genocídio. A autora afirma que a presença de marcadores étnicos e raciais, interseccionados com os de gênero, modifica a forma de compreensão da violência sexual. Smith (2014) argumenta que o estupro é uma ferramenta da dominação racial e colonial que submete toda comunidade de cor - rever a definição proposta por Lugones (2008) - ao terror sexual. Em contextos de dominação étnica, o controle simbólico e literal do corpo dos povos indígenas torna-se um instrumento de guerra importante. 
Em contrapartida, a vivência do luto e do sofrimento experimentados em eventos devastadores conduz a transformações na vida das interlocutoras, de modo que trajetórias atravessadas por episódios de extrema violência possam novamente ser habitadas. Trata-se do que Veena Das (2008a) definiu como "capacidade de suportar". Nesse processo, a dor pessoal que acompanhará os corpos e as enunciações das tembé-tenetehara por toda a vida converte-se em ação coletiva, em resistência étnica, em luta por direitos.

Essa "coletivização" torna-se visível dentro das clivagens evocadas na narrativa: o desespero de ter a filha desaparecida conduz a visões e intuições que não só aplacam o sofrimento da mãe, como reorganizam a gestão da busca, influenciando de forma excepcional o seu desfecho; a intervenção religiosa do rapaz evangélico dá forças para que mãe e filha possam retomar suas vidas; a dor da violência sexual e física ocorrida na juventude influencia sobremaneira o protagonismo de Carolina para obtenção de acesso à saúde para os membros da comunidade; o inefável dos eventos de extrema violência (Das 2008a) converte-se em necessidade política de narrar o que ocorreu, para que essas memórias não sejam apagadas, nem esquecidas.

Dona Joana, por sua vez, relata sua experiência pós-operatória em um hospital local, após fazer uma cirurgia no útero que demorara dois anos para ser agendada:

"depois eu fiquei naquele leito. Tinha uma mulher do meu lado, que ela não tinha ninguém, não tinha família, ninguém ia visitar. Aí a gente levava comida pra ela todo dia, meus filhos traziam o rancho pra mim e pra ela. Até que um dia a cama dela começou a encher de formiga, um ninho de formiga subindo pelo braço, pelo rosto e ninguém fazia nada. Até que eu chamei a enfermeira e disse: 'Vem cá, vocês vão deixar a cama dela desse jeito, é?! Não vão limpar a mulher, não?' Aí que a enfermeira foi fazer a limpeza dela. Depois disso essa mulher pegou piolho, não tinha quem cuidasse, a cama encheu de piolho. Eu fiquei desesperada, pensa se eu pegasse piolho naquele estado..."

Em contexto em que as violações de direitos ocorridas em hospitais são reais e prováveis, saber cuidar da saúde no contexto comunitário é essencial: rezar na cabeça de menino com febre; ministrar ervas medicinais para pessoas que adoecem ou são envenenadas; manter a gravidez ou interrompê-la quando as vidas da mãe e do bebê estão ameaçadas; e dar à luz pela intermediação de parteiras são exemplos de saberes e fazeres acionados no agenciamento de situações consideradas de risco, em que se sabe que o acesso à medicina ocidental tende a falhar.

Nesse sentido, os saberes de saúde e cuidado de si constituem um empreendimento que conforma resistências políticas, materiais e epistemológicas, em 
um contexto no qual o corpo vem à cena tanto como território de lutas e afirmações identitárias, quanto como alvo de opressões e estigmas. Ao contrário da visão de cuidado amplamente discutida na literatura produzida na área da enfermagem, pautada na atenção e medicalização de pessoas com doenças, ou deficiência, o cuidado tembé é holístico e alimenta o corpo de forma completa, por meio do sistema de saúde tradicional, da proteção espiritual, das lutas políticas por uma vida melhor, que acarretam uma corporeidade saudável. E esse corpo não se estrutura desconectado do ser indígena, com toda a carga política e epistemológica que essa identidade enseja.

Ferreira (2013) afirma que as determinações de gênero, classe, raça e etnia contribuem para o aumento da vulnerabilidade às doenças e para diferenciar o perfil epidemiológico das mulheres. Segundo a autora, em função de relações duplamente discriminatórias, as mulheres negras e indígenas possuiriam maior vulnerabilidade em saúde. Além disso, os contextos étnicos específicos de mulheres indígenas requerem um atendimento à saúde diferenciado, capaz de contemplar a diversidade.

Por fim, o último evento apresentado como revelador de processos de cuidado, cura e resistência também envolve relações entre mãe e filha. São episódios da trajetória de Carla, casada com um homem não indígena que vivia sob constantes ameaças por estar envolvido em atividades perigosas, que ninguém sabia do que tratavam, embora todos na família da interlocutora suspeitassem que envolviam serviços ilegais. Quando as ameaças começaram a se direcionar para a vida de Carla e de seus filhos, ela, o marido e as crianças foram obrigados a fugir às pressas, levando poucos pertences e sem informar ninguém sobre o lugar para onde iam, ou as condições em que ficariam. Durante todo o período em que esteve escondida, Carla e sua mãe, Dona Laura, viam-se em sonhos e por meio dessas visões, partilhadas por ambas, elas se tranquilizavam de que tudo estava bem.

Tempos depois, quando Carla finalmente pôde retornar a sua casa com a família, uma de suas filhas começou a insistir para que o pai passasse a frequentar a Igreja evangélica e que deixasse aquela rotina de perigos e incertezas. A menina finalmente conseguiu convencer o pai a assisti-la cantar em um dos cultos da igreja que frequentava e na manhã da apresentação ele vestiu-se todo de branco e os parentes de Carla ficaram surpreendidos e felizes com a iniciativa. Porém quando estava a caminho do culto, a ameaça se concretizou e o marido de Carla foi morto a tiros por um desconhecido.

Em meio a todo o pânico causado pela morte repentina, a filha de Carla pediu que todos fossem ao culto, pois ela cantaria em homenagem ao pai. Mesmo os parentes que não eram evangélicos atenderam ao pedido da menina e se dirigiram com muito pesar para o local onde ela se apresentaria. Segundo Dona Laura, "quando foi a vez dela, ela cantou tão alto e de um jeito tão lindo que todo mundo se emocionou, até quem não era da família se emocionou”. 
O canto da menina que havia acabado de perder o pai, naquele momento, trazia à cena pública o luto por uma ordem doméstica drasticamente desfeita e "coletivizava" a dor da perda, em uma gramática do corpo e do afeto que comoveu mesmo as pessoas que não partilhavam seu sofrimento. $\mathrm{O}$ ato da menina possui papel ativo na gestão do luto vivido e na reordenação da vida cotidiana, assim como as visões que conectavam mãe e filha no momento de migração forçada.

Os depoimentos apresentados não são ditos para qualquer pessoa, nem em qualquer lugar. $\mathrm{O}$ modo como a ação colonial etnocida incidiu sobre a vida do povo tembé-tenetehara implicou, no passado, na dissolução da vida comunitária, na proibição de declarar-se indígena e no silenciamento de saberes e memórias coletivas. Atualmente, esse processo se traduz pelo fato de que a maioria das interlocutoras idosas possuem antepassados que não conheceram e de quem nada sabem.

É com o intuito de romper com o etnocídio e a destituição da memória de seu povo que as mulheres tembé-tenetehara contam histórias de extrema violência no contexto dessa pesquisa: por meio do registro na produção antropológica elas esperam que essas memórias não sejam esquecidas nem apagadas, mas que, pelo contrário, permaneçam vivas na luta por direitos coletivos e por reconhecimento. Relatar as estratégias de agência e resistência e o protagonismo das interlocutoras frente a situações de poder assimétricas coaduna-se com esse objetivo.

De acordo com Taussig (1993), a reprodução da imagem dos povos indígenas como selvagens, irracionais e violentos é o que possibilita a propagação do terror colonial. Trata-se de uma operação mimética por parte do colonizador, que conduz a atos de extrema violência colonial, não importando se esse imaginário é verdadeiro ou não. As culturas do terror criam, desse modo, o que o autor denomina como espaços de morte, onde indígenas, africanos e brancos viram nascer o Novo Mundo. Segundo Taussig (1993), o terror é o mediador por excelência da hegemonia colonial.

O autor afirma que "as culturas do terror são nutridas pelo entremesclar do silêncio e do mito" (Taussig 1993: 30). Os efeitos paralisantes e silenciadores do terror encontrariam na narrativa sua primeira possibilidade de cura. Quando decidiram falar sobre as violências que marcaram de forma mais ou menos severa suas trajetórias, as tembé-tenetehara começaram a vencer a primeira imposição do terror, o silêncio. Conforme elucidou Dona Cássia: "Eu passei muito tempo calada, essas histórias guardadas em mim, me sufocando. Chegou um momento da minha vida que eu preciso falar, isso explodiu em mim, muitas vezes eu chorei lembrando de tudo, mas eu precisava dizer!"

Os corpos de mulheres tembé carregam, nesse sentido, a marca da violência, e suas trajetórias dizem das formas de agenciar, buscar alternativas e resistir. As interlocutoras constroem o "ser sujeito" a partir do enfrentamento de tais situações. 
Uma das interlocutoras, reconhecida como a "Capitoa" da aldeia "por ser uma das mais antigas dos nossos antepassados", relata que nos tempos antigos, quando houve grande incidência de hanseníase na região, ela conseguiu paralisar o avançar da doença no corpo de um membro da comunidade utilizando as propriedades do mucuracaá, uma planta medicinal que também é utilizada entre os tembé para combater o mau-olhado. Outras indígenas afirmam que uma mulher grávida que estivesse sob os cuidados da Capitoa estaria em boas mãos, uma vez que ela acompanhava a gestação desde os primeiros meses até a hora do parto, no qual a mulher era virada de lado e dava à luz enquanto a interlocutora rezava em sua barriga.

Durante uma das idas a campo, a mãe de uma criança que havia nascido há pouco tempo encontrava-se aflita, pois o bebê não parava de chorar e não costumava ser assim. Nesse momento, Dona Maria, sogra da mãe da criança, entrava na casa e, ao saber da situação, perguntou se a menina havia ido tomar banho de igarapé. Ao receber resposta afirmativa, a interlocutora disse:

"Minha filha, pegue alho, amasse e misture com álcool e deixe um tempo. Depois passe com o dedo na palma da mão da neném, na sola do pé, no braço e na coxa, em forma de cruz. Vai ficar um cheirinho ruim, mas não tem problema, ela vai melhorar. Ela deve ter visto alguma coisa no igarapé, criança é muito sensível, parece um pintinho novo. Quando eu era pequena, minha tia levava a gente pro igarapé, mas ela entrava primeiro, pedia licença pra mãe da água pra gente entrar e jogava o alho na água, aí o banho era sossegado".

A paçoca de gergelim preto "pisada" com hortelã é utilizada para "botar pra fora" (as indígenas não utilizam o termo "aborto"), principalmente quando a gravidez ameaça a vida da mãe ou quando o parto é de risco. Para mulheres grávidas que sentem dores, o chá de gengibre é ministrado. Para inflamações, especialmente em casos de problemas de próstata, o caroço de abacate mostra-se eficaz. Pessoas especializadas rezam na cabeça de crianças com febre. Bebês, quando morrem antes do batismo, choram durante sete dias e precisam ser batizados para que "descansem". A última prática mostra-se elucidativa da forma tembé de pensar a construção da "pessoa", a partir do ato de batizar a criança morta. Para os tembé-tenetehara não se deve negar às pessoas mortas, quando oriundas de famílias cristãs, o direito ao ritual de batismo que as forma e legitima.

As situações acima descritas, integrantes das observações de campo, revelam que mesmo enfrentando situações de precariedade e violência, as mulheres exercem seu protagonismo, instituindo o "ser sujeito", e encontram alternativas para agenciar situações de violência. O corpo e as múltiplas corporeidades 
que coexistem entre as interlocutoras são territórios privilegiados da resistência das indígenas mulheres e das formas de cuidar de si mesmas.

\section{FINALIZANDO, POR ENQUANTO (OU APENAS COMEÇANDO)...}

A estruturação do olhar antropológico sobre o campo, em diálogo com os conceitos e categorias referidas, foi essencial para a compreensão das interlocutoras como protagonistas de suas próprias histórias, não como vítimas passivas, desagenciadas e paralisadas diante de violações. Em contrapartida, a adoção de tais aportes teóricos não permite cair na armadilha de desconsiderar os processos de brutalização dos corpos, de colonização, de violação de direitos consecutivamente vivenciados e dramatizados na trajetória do povo tembé-tenetehara.

Pelo contrário, a partir do diálogo com as interlocutoras e teorias, o ponto de vista assumido pretende compreender os processos pelos quais violências vividas como eventos devastadores desdobram-se em mobilização social e luta por direitos, implicando enfrentamentos e resistências diante de situações de poder assimétricas. Acredita-se que a confrontação de tais atos, falas e teorias pode ser uma alternativa para a compreensão das desigualdades de forma mais nuançada, bem como uma forma de evitar estigmas e estereotipias sobre as interlocutoras com quem se dialoga.

$\mathrm{Na}$ noite em que contou sobre a história da filha, momentos antes, Dona Cássia disse o seguinte:

"O nosso povo foi muito massacrado no Prata. Morreu muita gente. A gente jamais podia dizer que era índio, até hoje nós vivemos discriminados. Hoje tá muito melhor, a gente vive junto, faz nossas festas, cuida uns dos outros e o nosso povo se alegra. Mas vive com a discriminação. Não podemos usar uma roupa, que já dizem que nós não somos índios. Eu vou dizer que eu sou uma portuguesa, sendo que eu não sou? Até tem gente que diz, mas eu não digo. Eu digo o que eu sou, eu sou tembé. Mas tem que viver com a discriminação".

Pode-se, a partir dessa fala, das vivências em campo e da bibliografia consultada, refletir sobre como o etnocídio tembé diz de um projeto de nação que extermina e massacra - como refere Dona Cássia - povos etnicamente diferenciados. E esse projeto se inscreve de forma violenta e diariamente atualizada nos corpos das indígenas mulheres. A história de dor e luta dos tembé mudou os modos de viver, enfrentar e cuidar praticados pelas mulheres. A reelaboração é imposta, porque implica em se proteger de violações, mas também é de resistência e cura, porque agencia e enfrenta o etnocídio a partir de cada vida e de cada corpo que busca existir. 


\section{BIBLIOGRAFIA}

BARATA, Camille Gouveia Castelo Branco, e Jane Felipe BELTRÃO, 2014, "Corporeidade e gênero em revistas brasileiras de ciências humanas (2008-13): limites e contribuições ao debate sobre povos indígenas a partir do caso tembé-tenetehara”, Espaço Ameríndio, $8(2): 11-48$.

BARTH, Fredrik, 2000, “Os grupos étnicos e suas fronteiras”, em Tomke Lask (org.), O Guru, o Iniciador e Outras Variações Antropológicas. Rio de Janeiro, Contra Capa Livraria, 25-67.

BELTRÃO, Jane Felipe, 2012, “Histórias 'em suspenso': os Tembé 'de Santa Maria', estratégias de enfrentamento do etnocídio 'cordial'”, Revista História Hoje, 1 (2): 195-2 12.

BOURDIEU, Pierre, 1977, Outline of a Theory of Practice. Cambridge, Cambridge University Press.

BRAH, Avtar, 2006, "Diferença, diversidade, diferenciação", Cadernos Pagu, 26: 329-376.

COMERFORD, John, 1999, Fazendo a Luta: Sociabilidade, Fala e Rituais na Construção de Organizações Camponesas. Rio de Janeiro, Relume-Dumará.

CSORDAS, Thomas J., 1990, “Embodiment as a paradigm for Anthropology”, Ethos, 18 (1): 5-47, disponível em < http://openwetware.org/images/5/54/Csordas.pdf > (última consulta em outubro de 2016).

DAS, Veena, 2008a, "El acto de presenciar: violencia, conocimiento envenenado y subjetividad”, em Francisco Ortega (org.), Veena Das: Sujetos del Dolor, Agentes de Dignidad. Bogotá, Universidad Nacional de Colombia, 217-250.

DAS, Veena, 2008b, “Lenguaje y cuerpo: transacciones en la construcción del dolor”, em Francisco Ortega (org.), Veena Das: Sujetos del Dolor, Agentes de Dignidad. Bogotá, Universidad Nacional de Colombia, 343-374.

ESTEBAN, Mari, 2004, Antropología del Cuerpo: Género, Itinerarios Corporales, Identidad y Cambio. Barcelona, Edicions Bellaterra.

FERREIRA, Luciane Ouriques, 2013, "Saúde e relações de gênero: uma reflexão sobre os desafios para a implantação de políticas públicas de atenção à saúde da mulher indígena”, Ciência e Saúde Coletiva, 18 (4): 1151-1159.

GEERTZ, Clifford, 1973, The Interpretation of Cultures. Nova Iorque, Basic Books.

GEERTZ, Clifford, 2007, O Saber Local: Novos Ensaios em Antropologia Interpretativa. Rio de Janeiro, Vozes.

GIDDENS, Anthony, 1984, The Constitution of Society. Cambridge, Polity Press.

GOMES, Mercio Pereira, 2002, O Índio na História: O Povo Tenetehara em Busca da Liberdade. Petrópolis, Vozes.

KLEBA, Maria Elisabeth, e Agueda WENDAUSEN, 2009, "Empoderamento: processo de fortalecimento dos sujeitos nos espaços de participação social e democratização política”, Saúde e Sociedade, 18 (4): 733-743, disponível em < http://www.revistas.usp.br/sausoc/article/viewFile/29498/31358 > (última consulta em outubro de 2016).

LUGONES, María, 2008, "Colonialidad y género", Tabula Rasa, 9: 73-101.

MAGNANI, José Guilherme, 2009, "Etnografia como prática e experiência”, Horizontes Antropológicos, 15 (32): 129-156.

McClinTOCK, Anne, 2010, Couro Imperial: Raça, Gênero e Sexualidade no Embate Colonial. Campinas, Editora da Unicamp.

OLIVEIRA, João Pacheco de, 1998, "Uma etnologia dos 'índios misturados'? Situação colonial, territorialização e fluxos culturais”, Mana, 4 (1): 47-77, disponível em < http://www 
.scielo.br/scielo.php?pid=S0104-93131998000100003\&script=sci_arttext $>\quad$ (última consulta em outubro de 2016).

OLIVEIRA, João Pacheco de, 2004, "Pluralizando tradições etnográficas: sobre um certo mal-estar na Antropologia”, em E. J. Langdon e L. Garnelo (orgs.), Saúde dos Povos Indígenas: Reflexões sobre Antropologia Participativa. Rio de Janeiro, Associação Brasileira de Antropologia/Contra Capa, 9-32.

OLIVEIRA, Roberto Cardoso de, 2005, "Identidade étnica, reconhecimento e o mundo moral”, Revista Anthropológicas, 16 (2): 9-28.

OLIVEIRA, Roberto Cardoso de, 2006, O Trabalho do Antropólogo. São Paulo, Editora Unesp. QUIJANO, Aníbal, 2005, "Colonialidad del poder, eurocentrismo y América Latina”, em Edgardo Lander (org.), La Colonialidade del Saber: Eurocentrismo y Ciencias Sociales. Perspectivas Latino-Americanas. Buenos Aires, CLACSO, 227-278.

SCOTT, Joan, 1995, "Gênero: uma categoria útil de análise histórica", Educação e Realidade, 20 (2): $71-99$.

SEGATO, Rita Laura, 2003, Las Estructuras Elementales de la Violencia: Ensayos sobre Género entre la Antropología, el Psicoanálisis y los Derechos Humanos. Buenos Aires, Universidad Nacional de Quilmes/Prometeo 3010.

SMITH, Andrea, 2014, "A violência sexual como uma ferramenta de genocídio", Espaço Ameríndio, 8 (1): 195-230.

SPIVAK, Gayatri Chakravorty, 2010, Pode o Subalterno Falar? Belo Horizonte, Editora UFMG.

TAUSSIG, Michael, 1993, Xamanismo, Colonialismo e o Homem Selvagem: Um Estudo sobre o Terror e a Cura. Rio de Janeiro, Paz e Terra.

VIANNA, Adriana, e Juliana FARIAS, 201 1, "A guerra das mães: dor e política em situações de violência institucional", Cadernos Pagu, 37: 79-1 16.

VIDAL, Lux, 2000, Grafismo Indígena: Estudos de Antropologia Estética. São Paulo, Studio Nobel, FAPESP.

WAGLEY, Charles, e Eduardo GALVÃO, 1955, Os Índios Tenetehara: Uma Cultura de Transição. Rio de Janeiro, Ministério da Educação e Cultura. 